\title{
Experimental research on obtaining pelletized feed recipes with applicability in semi-intensive aquaculture systems
}

\author{
Iulian Voicea ${ }^{1 *}$, Corina Ioana Moga ${ }^{2}$, Sorin-Ștefan Biriș $^{3}$, Gabriel-Alexandru Constantin ${ }^{3}$, \\ Sorin Boruz ${ }^{4}$, and Mihai Gabriel Matache ${ }^{1}$ \\ ${ }^{1}$ National Institute of Research - Development for Machines and Installations Designed for \\ Agriculture and Food Industry - INMA Bucharest, 6, Ion Ionescu de la Brad, sector 1, Romania \\ ${ }^{2}$ DFR Systems S.R.L., 46, Drumul Taberei, Bucharest 061392, Bucharest, Romania \\ ${ }^{3}$ Politehnica University of Bucharest, Faculty of Biotechnical Systems Engineering, Romania \\ ${ }^{4}$ University of Craiova, Romania
}

\begin{abstract}
Romanian aquaculture can be economically sustainable and viable if the farm is profitable, the farm's income is secure, and the products are accepted by customers. In many cases, improving environmental sustainability can lead to optimizing economic sustainability. For example, a more efficient use of food and nutrients or reduced water and energy consumption are not only beneficial for the environment, but can also reduce costs. Growth in polyculture system, which represents the growth of several species of fish in the same space (pond, pool, basin, etc.), and diversification of supply can increase consumer confidence and thus economic sustainability. The diet must provide the fish with the nutrients necessary for growth (proteins with a plastic role) and provide the energy necessary for physiological processes. Quality food ensures good development, facilitates reproduction and prevents extremely harmful diseases in an aquaculture system. The paper presents a series of experimental recipes for pelletized feed made using an experimental model of small capacity. Nutrient pellets made for feeding fish from the Cyprinid family were analyzed in terms of gross energy value, ash content, moisture, mechanical durability over time, bulk density etc.
\end{abstract}

\section{Introduction}

Aquaculture, in the broadest sense of the word, means the technology of growing organisms in the aquatic environment, useful to humans, in which the predominant role belongs to fish, algae, molluscs and crustaceans. Aquaculture is currently considered as the science that deals with the study of biological bases and the development of biotechnical methods based on which aquatic organisms multiply, grow, develop in natural or anthropogenic

* Corresponding author: voicea iulian@yahoo.com 
aquatic basins, $[1,2]$. Aquaculture is increasingly contributing to the world's production of aquatic food, given that, for most wild fish stocks, sustainable exploitable limits are now almost reached or even exceeded. Semi-intensive growth of fish or other aquatic organisms is based on natural productivity and / or enriched by fertilization of anthropogenic ecosystems, respectively on the administration of additional food. In fact, semi-intensive cultivation involves obtaining a fish biomass with low production costs due to the use of inexpensive inputs. For the aquaculture in our country, this system is widely used, contributing to obtaining food-safe products. In this case, it is obvious the intervention of anthropogenic factors to create favourable conditions for fish farming, such as: own system of supply and evacuation of water from the ecosystem (allows the replacement of $10-15 \%$ of water), application of treatments to improve physical-chemical quality of water and soil (application of organic and inorganic fertilizers, amendments, etc.) and the use of aeration systems to maintain optimal concentrations of dissolved oxygen in water, [3,4].

In these growing systems only one species can be raised (monoculture) but it is agreed to grow several fish species that capitalize on complementary trophic niches (polyculture). Taking into account the cost / benefit ratio (the ratio between inputs / outputs) it can be can appreciated that this system can be applied in the case of farms with fish production on a smaller scale (but higher than $>500 \mathrm{~kg} / \mathrm{ha}$ ), [5,6,7].

Raising different species of fish together in polyculture is a widespread system in many parts of the world. It is estimated that this system leads to obtaining productions clearly superior to the monoculture system, as a result of the maximum exploitation of all trophic niches. In order to maximize fish production in polyculture systems, it is essential to know the relationships established both between fish species and between fish and the environment. The farmer's choice of the most appropriate species of fish or other aquatic organisms, age classes, population densities, fertilization regime, feed ensures the success of such a production system, [8,9]. Usually, the efficiency of using the resources from the same pond increases as the fish species have different nutritional spectrum. Increasing production efficiency is achieved when the metabolic wastes of one species are used as food by another. Choosing the most suitable species for polyculture will minimize the antagonistic relations and maximize the synergy of the pond relations, leading to the increase of the availability of food resources for the cultivated species and at the same time the improvement of the environmental conditions. The specialized literature describes a synergistic relationship in the polyculture of plankton-eating fish - carp that appears as a result of the activity of the benthos agitation carp, thus facilitating the efficient use of organic and inorganic matter. This process significantly reduces the accumulation of ammonia and nitrites, as well as the organic load at the bottom of the water. Through this movement, nutrients are more available for macroscopic algae which, in turn, can be used in fish feed. More intense photosynthesis also leads to better oxygenation, increased $\mathrm{pH}$ and efficient nitrification.

Feeding has the most important impact on the results in fish farms, because the quantity and quality of the fish stock is directly proportional to its diet.

But fodder also has the highest production cost, having the greatest influence on profit, which is why the correct choice of fodder is crucial. Carp can be fed both complete and incomplete combined feed.

In salmon farms, the use of combined feed is an old practice, due to the special economic and ecological impacts. Increased productivity in this sector is constantly demanding better and better feed, as the results of intensive aquaculture (health, fish growth and development) are closely correlated with feed quality. In addition, environmental legislation requires that these feeds have as little impact on water quality as possible, especially since in some more developed countries each aquaculture farm is required to provide a certain amount of feed that can be used in one season, and the farmer is forced to make the most of this amount (sometimes quite limited). 
In carp farms, there are extended reserves concerning increasing productivity. The majority of farms in the central and eastern Europe have 50 years old technologies, that are based on large areas of water coverage, $n$ natural productivity of ponds and on additional feeding.

Pelleting / granulating is one of the best treatments for combined animal feed. Pelleting translates as a process of compressing materials that have been grinded to the intended sizes, by feeding them into an equipment and, by means of compaction rollers, forcing them to pass through the cylindrical orifices of a plane or ring dies. By pelleting the combined feed, bulk density increases, the feed is homogenous, harmful organisms are destroyed, and better handling and distribution are ensured. [10,11]

\section{Material and method}

The paper studies four different recipes of pelleted feed for aquaculture, especially for the cyprinid family. Pelleting was performed using an experimental model installation model for obtaining granulated / pelleted feed for aquaculture. The main technical characteristics of the pelleting / granulating press are the following: supply voltage: $230 \mathrm{~V}$, electric motor power: $2800 \mathrm{~W}$, maximum speed: $1400 \mathrm{rpm}$, production capacity: $100 \mathrm{~kg} / \mathrm{h}$, die orifice diameter: 3-8 $\mathrm{mm}$.

\section{Recipe 4}

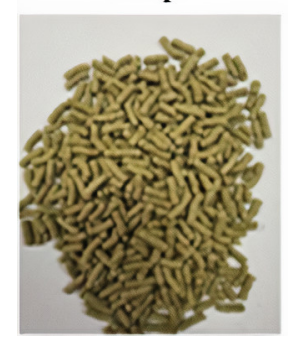

\section{Pelleted feed}

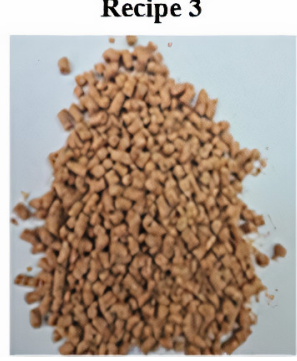

Recipe 2

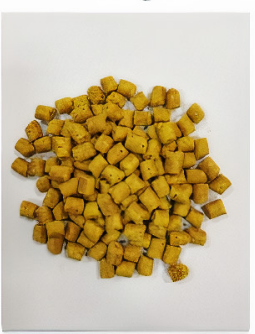

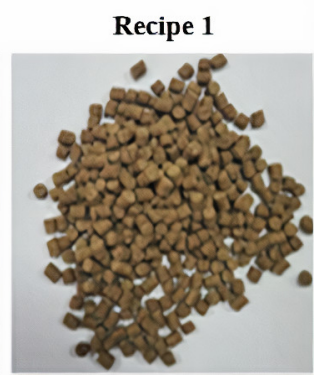

Fig.1. Pellets resulted from the four feed recipes for cyprinids

The basis for the four pelleted feed recipes was represented by cereal material: sun flower seeds, corn, wheat, soybean. For an adequate binding and in order to increase the energy intake, additive materials were added, such as: fish flour, vitaminized calcium, gum arabic colouring, vitamin $\mathrm{C}$, roasted hemp, krill flour, sweet corn starch with integrated starch, yeast extract to increase digestibility. Therefore, the composition of recipe 1 included: $50 \%$ sunflower, $25 \%$ corn, $10 \%$ wheat, $5 \%$ soybean, $10 \%$ additives (fish flour, vitaminized calcium, black gum arabic colouring, roasted hemp, yeast extract, starch); recipe 2 included: $65 \%$ corn, $15 \%$ sunflower, $5 \%$ wheat, $15 \%$ additives (fish flour, vitaminized calcium, yellow gum arabic colouring, vitamin C, sweet corn starch with integrated starch, yeast extract, starch). In the composition of recipe 3, we have the following ingredients: 20 $\%$ sunflower $50 \%$ corn, $10 \%$ wheat, $10 \%$ soybean, $10 \%$ additives (fish flour, vitaminized calcium, red gum arabic colouring, krill flour, yeast extract, starch); and recipe 4 included the following: $10 \%$ corn, $10 \%$ wheat, $10 \%$ soybean and $60 \%$ additives $(20 \%$ was represented by fish flour + vitaminized calcium + green gum arabic colouring + vitamin $\mathrm{C}$ + roasted hemp + yeast extract, and $40 \%$ starch + algae extract + spirulina + floatability extract).

For a faster determination of the moisture of the 4 types of pelletized feed recipes for aquaculture (cyprinids), a KERN thermobalance was used. The device uses the method of drying materials by heating the sample by means of electromagnetic waves with infrared wavelengths, produced by a special lamp. During drying, water is removed from the sample 
in the form of vapour, the sample being permanently weighed by an analytical balance existing in the apparatus. This infrared drying method is a thermogravimetric method for rapidly determining moisture.

The ash content from the 4 types of pellets was determined using the calcination furnace $[2,5]$. Thus, the samples were subjected to the calcination process according to the following stages:

$>$ Weighing the samples using an analytical balance (the mass of the sample should be more than $1 \mathrm{~g}$ );

$>$ Establishing the parameters of the program, namely increasing the temperature inside the calcination furnace at a rate of $5{ }^{\circ} \mathrm{C}$ after the following program: raising the temperature to $250{ }^{\circ} \mathrm{C}$ in a period of $30-50$ minutes, followed by maintaining the temperature for 60 minutes, then an increase of temperature from $250{ }^{\circ} \mathrm{C}$ to $550{ }^{\circ} \mathrm{C}$ in a period of 30 minutes, followed by keeping it at the same temperature for 120 minutes and lowering it to a temperature below $30^{\circ} \mathrm{C}$ from where the samples are taken with a special tong and placed in the desiccator;

$>$ After the samples were cooled for 24 hours in the desiccator, the ash content is determined for each pellet sample.
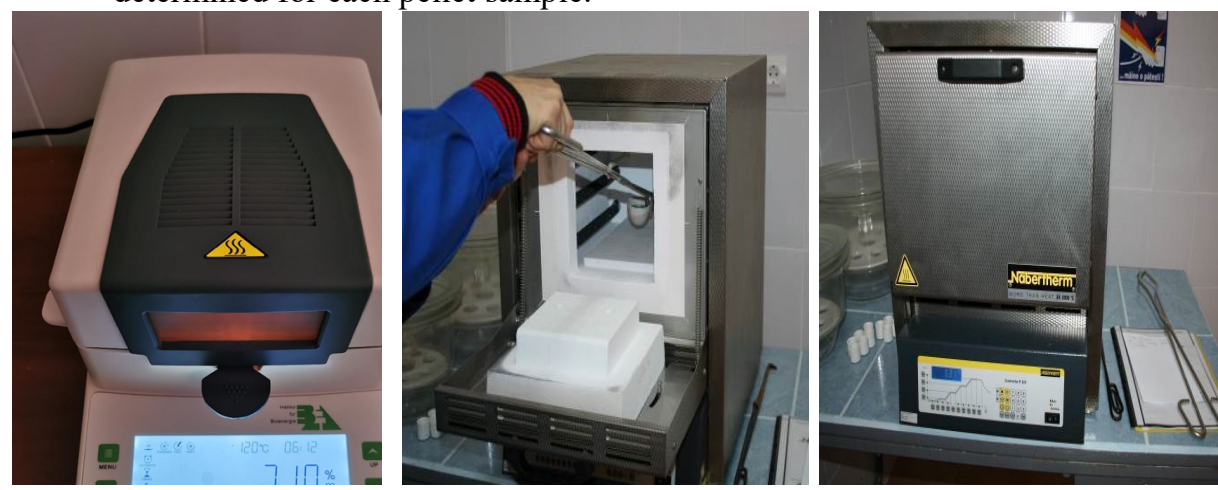

Fig. 2. Determining moisture and ash content

The determination of the gross energy value of the feed pellets was performed with the help of a CAL 3K-F calorimetric system, and the durability of the pellets was calculated using a TUMBLER 1000 laboratory system and the method used was 500 complete rotations during $10 \mathrm{~min}$.
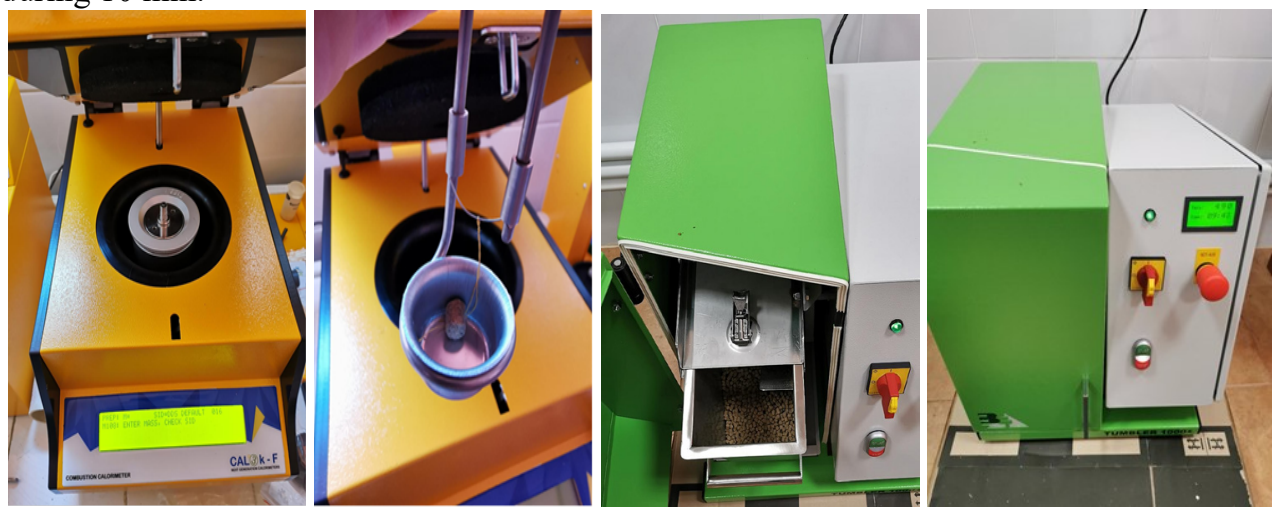

Fig. 3. Determination of calorific value and durability of feed pellets

\section{Results}


By using the laboratory equipment and test methods described above, the ash content, the moisture of the feed pellets, the gross energy value, the bulk density and the mechanical durability of the 4 types of pellet recipes were determined. The results obtained for the ash content are presented in figure 4 , for each feed recipe being performed 4 distinct measurements.

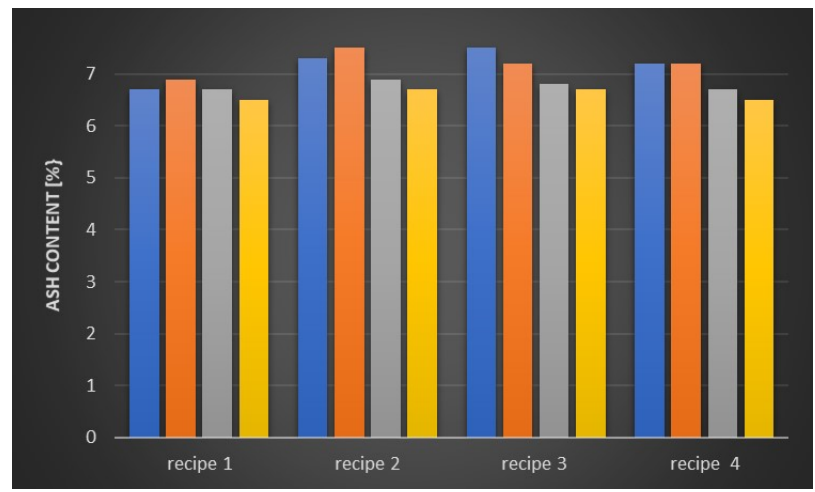

Fig. 4. Percentage of ash content for aquaculture feed recipes

In Table 1 are presented the results obtained for bulk density, moisture and gross energy value.

Table 1. Results obtained for the four types of pelleted feed

\begin{tabular}{|c|c|c|c|}
\hline $\begin{array}{c}\text { Pelleted } \\
\text { feed recipe }\end{array}$ & $\begin{array}{c}\text { Bulk density } \\
{\left[\mathbf{k g} / \mathbf{m}^{3}\right]}\end{array}$ & $\begin{array}{c}\text { Moisture } \\
{[\%]}\end{array}$ & $\begin{array}{c}\text { Gross energy } \\
\text { value } \\
{[\mathbf{M J}]}\end{array}$ \\
\hline \multirow{4}{*}{ Recipe 1 } & 596.28 & 6.6 & 20.6 \\
\cline { 2 - 4 } & 597.36 & 7.1 & 19.5 \\
\cline { 2 - 4 } & 598.12 & 7.4 & 19.7 \\
\hline \multirow{4}{*}{ Recipe 2 } & 588.12 & 7.2 & 19.5 \\
\cline { 2 - 4 } & 586.27 & 7.5 & 19.2 \\
\hline \multirow{3}{*}{ Recipe 3 } & 587.56 & 7.6 & 18.8 \\
\cline { 2 - 4 } & 496.47 & 7.3 & 19.1 \\
\cline { 2 - 4 } & 498.76 & 7.1 & 18.6 \\
\hline \multirow{5}{*}{ Recipe 4 } & 504.12 & 7.9 & 18.7 \\
\cline { 2 - 4 } & 85.32 & 6.9 & 17.8 \\
\cline { 2 - 4 } & 79.12 & 6.5 & 16.9 \\
\hline & 84.29 & 6.8 & 17.5 \\
\hline
\end{tabular}




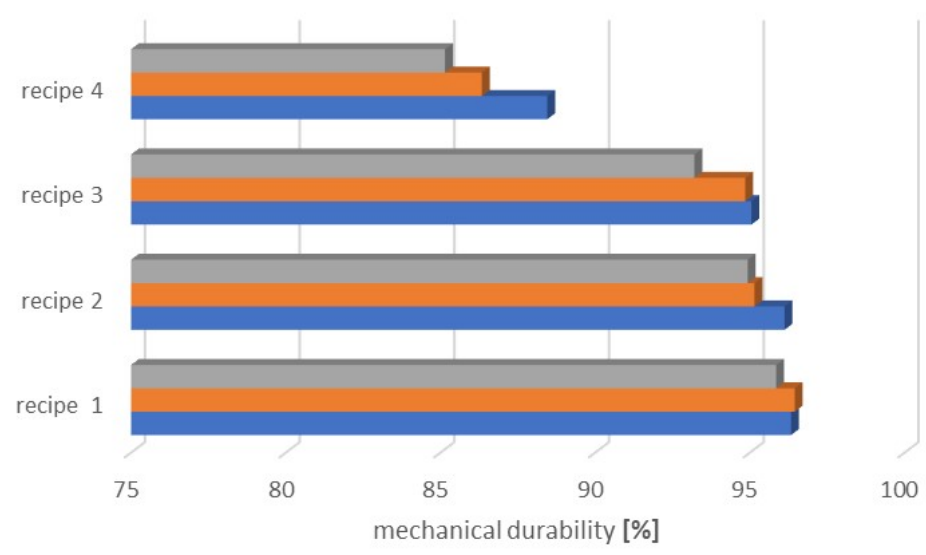

Fig. 5. Mechanical durability for the four aquaculture feed recipes

Figure 5 shows the mechanical durability of the 4 types of feed pellets obtained during the experiments.

\section{Conclusions}

Following the analysis of the experimental data presented above, the following conclusions can be drawn:

1. The average ash content for the four types of pellet recipes was between 6.7 (recipe 1) and 7.1 (recipe 2).

2. The average bulk density varied between $82.91 \mathrm{~kg} / \mathrm{m}^{3}$ (recipe 4) and $597.25 \mathrm{~kg} / \mathrm{m}^{3}$ (recipe 1).

3. The gross energetic value for recipe 1 was $19.93 \mathrm{MJ}$, for recipe 2: $19.19 \mathrm{MJ}$, recipe 3: $18.8 \mathrm{MJ}$ and 17.4 $\mathrm{MJ}$ for recipe 4.

4. The mechanical durability of the feed pellets was appropriate, also due to the fact that each recipe had in its composition starch as a food additive binder. The maximum mechanical durability was found in recipe 1 being $91.26 \%$ and the minimum in recipe $4: 86.64 \%$.

5. It can be stated that the 4 types of pellet recipes presented laboratory results appropriate as values with the pellets currently found on the market at this time, being used separately experimentally in feeding cyprinids for the study of digestibility and optimal nutritional assimilation of fish.

Acknowledgement: This work was supported by the Romanian Research and Innovation Ministry, through NUCLEU Programme, Project "PN 191002 03: " Researches on the intensive polyculture growth of fish and the complex valorisation of aquatic bioresources (plants)", contract no. $5 \mathrm{~N} /$ 07.02.2019.

\section{References}

1. K. Liua, J. Frost, T. Welker, F. Barrows, Animal Feed Science and Technology, 273, (2021).

2. I. Gageanu, D. Cujbescu, C. Persu, Gh. Voicu, Proceedings of $17^{\text {th }}$ International Scientific Conference Engineering for Rural Development - Jelgava, 17 (2018). 
3. M.G.Jayaram, H.P.C.Shetty, Aquaculture, 23 (1981).

4. W. Y.Moa, Z. Chenga, W. M. Choia, Y. B. Man, Y. Liu, M. H. Won, Marine Pollution Bulletin, 85, 2 (2014).

5. I. Găgeanu, C. Persu, D. Cujbescu, G. Gheorghe, Gh. Voicu, Proceedings of $18^{\text {th }}$ International Scientific Conference Engineering for Rural Development, 18 (2019).

6. P.Chukwulozie, I. Chigoziri., J. Lekwuwa, C. Jude, Heliyon, 5, 6 (2019).

7. J. Baea A. Hamidoghlia, S. Wona, W. Choia, W. Kim, Aquaculture, 525 (2020).

8. I. Găgeanu, P. Cârdei, M. Matache, Gh. Voicu, INMATEH Agricultural Engineering Journal, 59, 3 (2019).

9. T. Synnøve, M. Oehmeace, M. Sørensen, G. Hee, Aquacultural Engineering, 44, 1 (2011).

10. P. Cardei, I. Găgeanu, Gh. Voicu, M. Matache, INMATEH Agricultural Engineering Journal, 58, 2 (2019).

11. G. P. Salze, A. Davis, Aquaculture, 437, 1 (2015). 